\title{
Chitin and Lignin: Old Polymers and New Bio-Tissue- Carriers
}

Pierfrancesco Morganti ${ }^{1 *}$, Gianluca Morganti ${ }^{2}$, Vladimir E Yudin ${ }^{3}$ and Hong-Duo Chen ${ }^{4}{ }^{1}$ Academy of History of Healthcare Art, 00186 Rome, Italy and ChinaMedical University, 110001 Shenyang, China.

${ }^{2}$ ISCD Nanoscience Center 00165 Rome, Italy.

${ }^{3}$ Institute of Macromolecular Compounds, Russuan Academy of Sciences, 199004 Saint Petersburg, Russia.

${ }^{4}$ Department of Dermatology, The First Hospital of China Medical University, Key Lab of Immuno dermatology, National Health Commission Ministry of Education 110001 Shenyang China.

*Corresponding Author: Pierfrancesco Morganti, Academy of History of Healthcare Art, 00186 Rome, Italy and China Medical University, 110001 Shenyang, China.

Received date: August 16, 2021; Accepted date: September 28, 2021; Published date: October 06,2021

Citation: P Morganti, G Morganti, V E Yudin and H-D Chen. (2021) Chitin and Lignin: Old Polymers and New Bio-Tissue- Carriers. J. Dermatology and Dermatitis. 6(3); Doi: 10.31579/2578-8949/083

Copyright: @2021 Pierfrancesco Morganti, This is an open-acscess article distributed under the terms of The Creative Commons. Attribution License, which permits unrestricted use, distribution, and reproduction in any medium, provided the original author and source are credited.

\begin{abstract}
Worldwide consumers are nowadays much more focusing on their wealth and appearance, having increased their worry caused from the pollution, plastic wastes and the earth' disasters further increased for the COVID19 pandemic. This trend has created an heightened demand for products which, formulated with natural and functional ingredients and carried by sustainable delivery systems, should be produced and packed with biodegradable compounds. The paper suggests to formulate innovativecosmetic and medical products based on the use of carriers made bybiodegradable polysaccharide-tissues embedded by micro-nanoparticles of chitin nanofibril-nanolignin complexes, encapsulating different activeingredients. Thus, data on chitin, lignin and their complexes are reported and discussed, focusing the attention on their possible use to make innovative products, characterized for their effectiveness, safeness, and biodegradability.
\end{abstract}

Keywords: Chitin Nanofibrils; lignin, polyhydroxyalkanoate; polylactic acidnanoparticles; beauty market; surgical maskl; waste; pollution; environment; COVID-19

\section{Introduction}

The worldwide previsional increase of population to 9.15 billion with a contemporary increase of aging people projected to range 1.5 billion by 2050 [1], has created a major and different need for food, cosmetics, drugs and medical devices with a consequent production of a great quantity of plastic waste. Thus, the worldwide Beauty \& Personal care market valuewas of USD 483 billion in 2020 with a prediction to exceed USD 784.6 billion by 2027 with an annual grow rate(CAGR) of $4.75 \%$ in the 2020-2027 forecast period (Figure 1) [2,3], while the health and wellness food market is projected to grow to USD 235.94 million. 


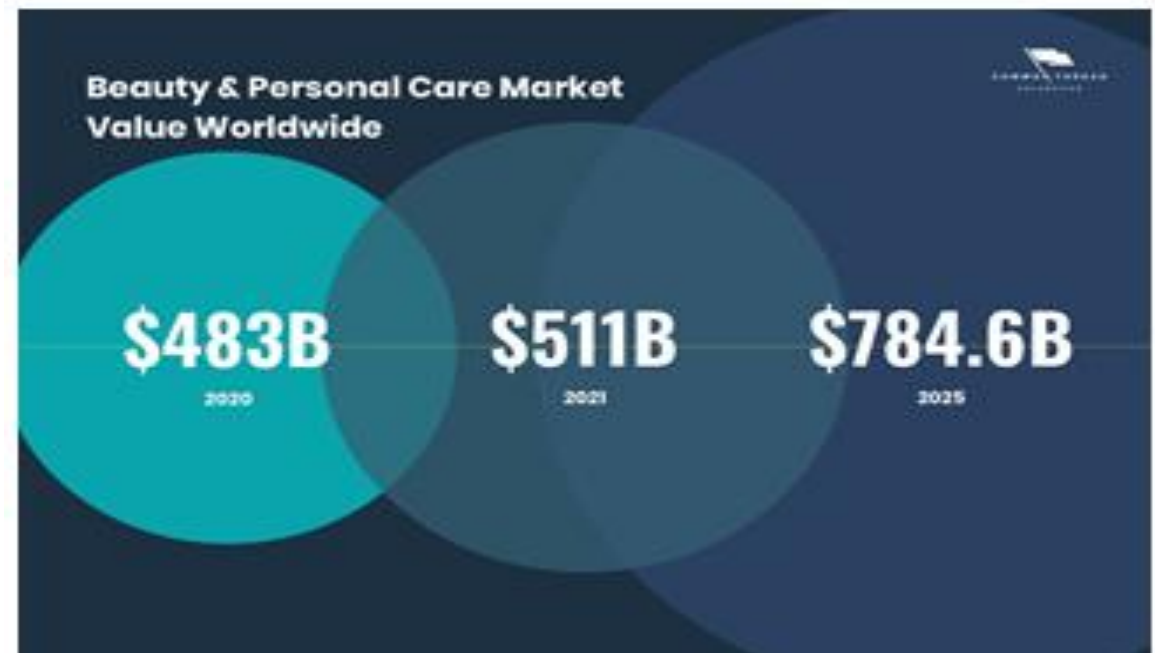

\section{Segment Revenue \& Growth Rate within the Beauty Industry}

$-\operatorname{son}-2005$

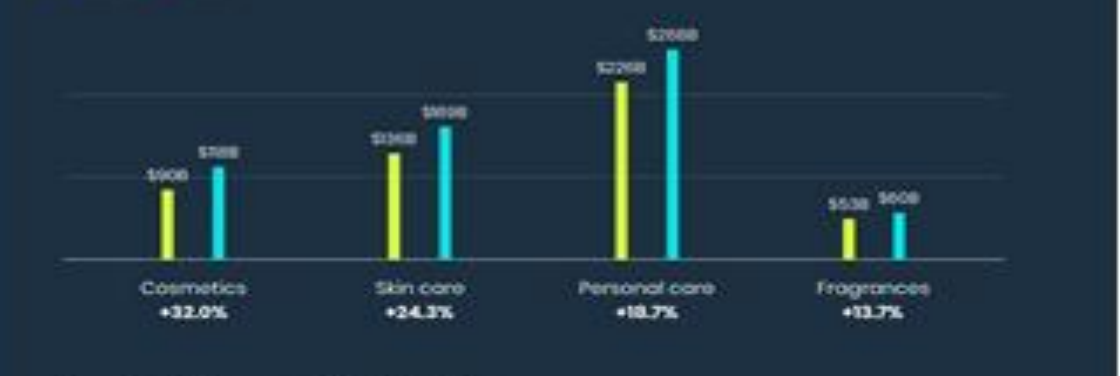

\section{Market Shares Worldwido}

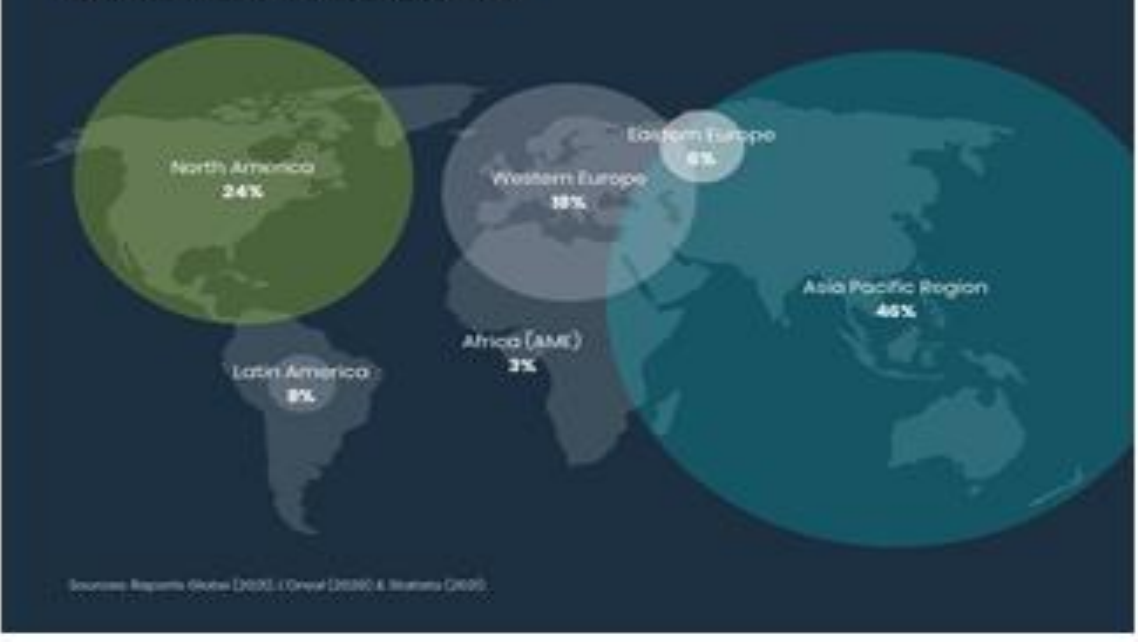

Figure 1: Previsional Beauty and personal market from the forecast period2020/2025(by the courtesy of Roberts-Common Threats [2]

This growth, further increased from the COVID-19 pandemic, is due to the women and men 'research of an healthy and juvenile aspect, also because "looking old" or "ugly" is considered to have negative effects on self-esteem and social Interactions [4]. Unfortunately, the major consumption of theseproducts has been also increased by the production of plastic waste which, invading lands and oceans, are provoking negative impacts on the Earth' ecosystems, causing environmental climatic disasters and serioushuman health problems $[5,6]$. Just to remember the global cosmetic industryproduces every year around 120 billion units of packaging much of which isnot recycled [7]. Thus the necessity to change our way of living going versusa zero waste society. We have to leave the linear economy by which raw materials are collected and transformed into products to be used anddiscarded, for adopting the circular economy based on the $3 \mathrm{R}$ approach of reducing, reusing and recycling at zero waste [8] (figure 2). 


\section{Linear economy}

\section{Chain economy}

\section{Circular economy}
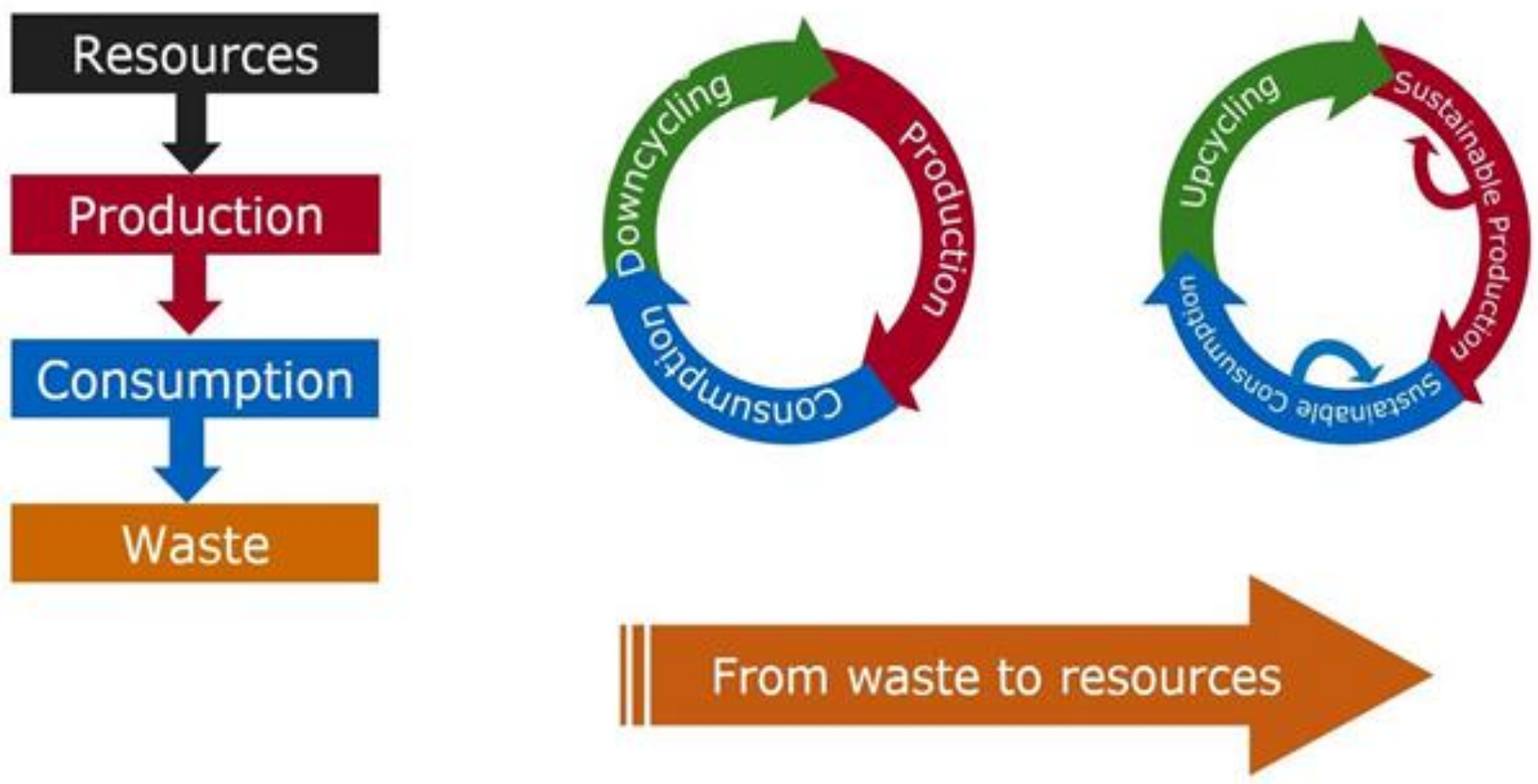

Figure 2: from linear to circular economy at zero waste

Therefore, the urgent need to rethink the plastic production and consumption' systems reducing, substituting, recycling and disposing, the relative goods [8].In the meantime, it should be necessary to take the opportunity for using all the actual waste bio-based materials to realize valuable and biodegradable bio-products, always remembering that biobased materials are not necessarily compostable or biodegradable [9].

It is in fact, to underline that food waste, which accounts for nearly $60 \%$ of allthe bio-waste produced, is rich of active ingredients as vitamins and minerals as well as of precious polymers, including biodegradable polysaccharides. It represents a precious raw material to make, for example, not only smart non-woven tissues and films for skin/body repairing [10,11] and food and cosmetic packagings [12], but also smart carriers and innovative products [13, 14].

Among the polymers obtainable from waste, it is increasing a global interestfor Chitin and Lignin with all their derived compounds [15, 16].

Thus, some activities of Chitin nanofibrils $(\mathrm{CN})$ and Nano-Lignin(LG) will be reported, focusing the attention on the possibility to make different polymeric micro-nanoparticles (PL)which, embedded into biodegradable non-woven tissues and films, could be used as innovative carriers of Medical and Cosmetic use.

\section{Chitin}

Alpha-Chitin is a linear nitrogen-bearing biological polymer consisting of sugar molecules bonded together to form long polysaccharide chains. It consists of an sugar-like polymer of beta- [1, 4]-linked linear chains composed of more than 5,000 N-acetyl glucosamine units, representing the second most abundant natural polymer in Earth after cellulose [17]. In effect, chitin may be described as cellulose with one hydroxyl group on eachmonomer, replaced by an acetyl-amine group (fig.3).The polymer, as an unbranched chain of glucose, is recovered in many mineralized biological tissues combined with proteinaceus materials and organized in sheets of antiparallel polymeric chains (fig 4).These chains, held together by a large number of hydrogen bonds give to chitin an increased tensile strength. Its complex structure, in fact, provides the structural backbone of insect cuticles, crustacean exoskeletons, cephalopod shells, overing surfaces ofmany other living organisms and acting also as support of fungal, yeast and algae' cell walls 


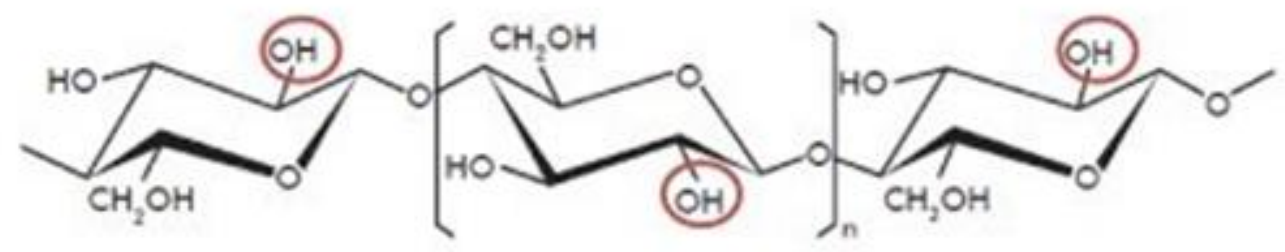

Cellulose

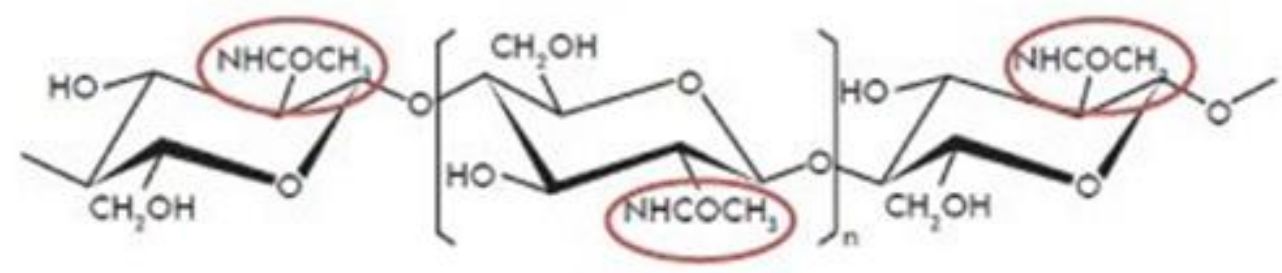

\section{Chitin}

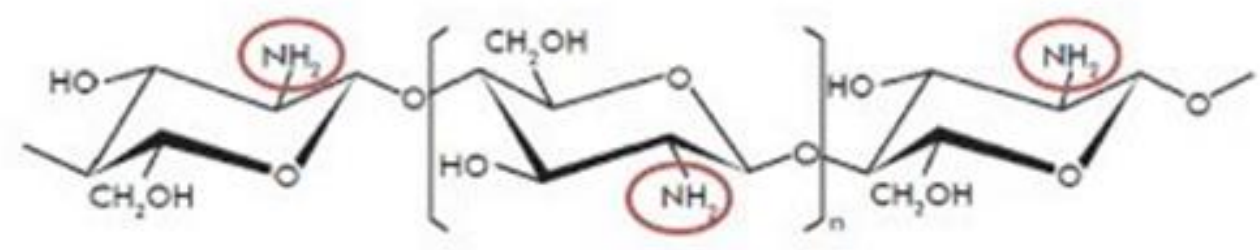

\section{Chitosan}

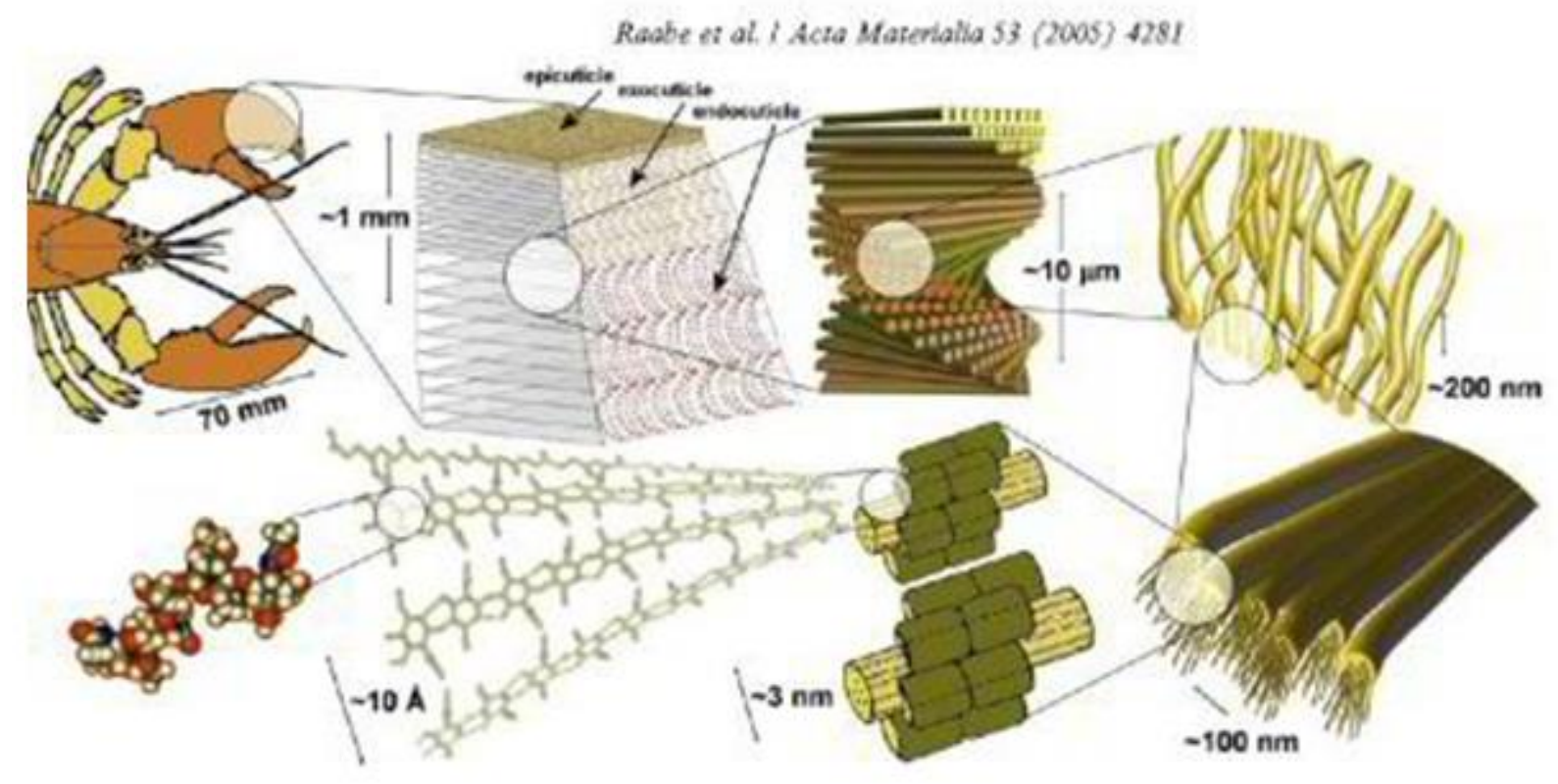

Figure 4: The multilayered structure of chitin organized in Nanofibrils entrapped by proteic material (by the courtesy of Raabe et al) 
Therefore, the around 20 chains of Chitin, aggregated in the form of microfibrils, cross-linked with other components of the cell wall, are made by a complex hierarchical structure arranged in such a way to represent a structural biomaterial of high industrial interest for its particular mechanical properties. It, in fact, results useful to develop innovative natural composites when combined, for example, with its deacetylated form chitosan or with other polymers, including polylactic acid (PLA) and polyhydroxyalkanoates (PHA) [18, 19]. However both Chitin and Chitosan have a great economic value because of their versatile biological and chemical activities, being alsobio- and eco-compatible, biodegradable, nontoxic nor allergizing agents [20, 21].Additionally the properties of these polymers, which depend from their selected origin and manufacturing process, are notably increased when they are used at micro-nanosize demension and purest crystallinform with a controlled grade of de-acetylation. At this purpose, our research group have produced pure Chitin nanofibrils $(\mathrm{CN})$ and Chitosan obtained bya sustainable patented process at practically zero waste.

At this purpose, both $\mathrm{CN}$ and Chitosan were made from crustacean chitin of food grade, treating the polymeric powder by acid or alcaline solutions respectively, under continuous stirring at controlled temperature. The residuewaste of nano-chitin and nano-chitosan at the last productive step, was practically zero. The remaining final exhausted powder, in fact, was used as plant fertilizer while the alkaline and acid solutions, mixed each to other, were used to produce a low quantity of sodium chloride. However, the $2 \%$ water suspension, obtained from the process with a $\mathrm{pH}$ interval between 2 and 4,contained around 300 trillions of chitin micronanocrystals per milliliter with a mean dimension of $240 \times 7 \times 5$ nanometers (fig 5),covered by positive charges [22,23].The presence of the positive chargeson the chitin surface, has given the possibility to produce block co-polymeric micro/nanoparticles (PL) by its self-assembling (ionic gelation method) with electronegative polymers, including hyaluronic acid and Lignin (fig 6) [24].

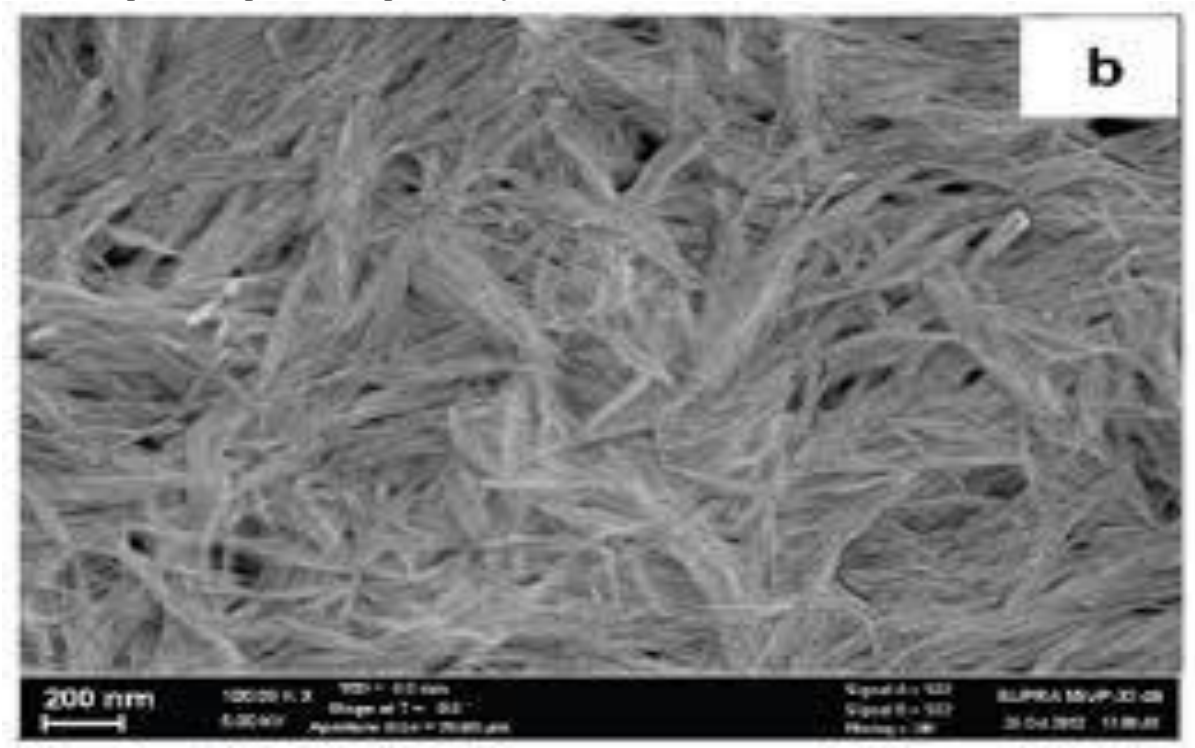

Figure 5: Crystallin needle-like structure of chitin nanofibrils (by the courtesy of Yudin et al [23])

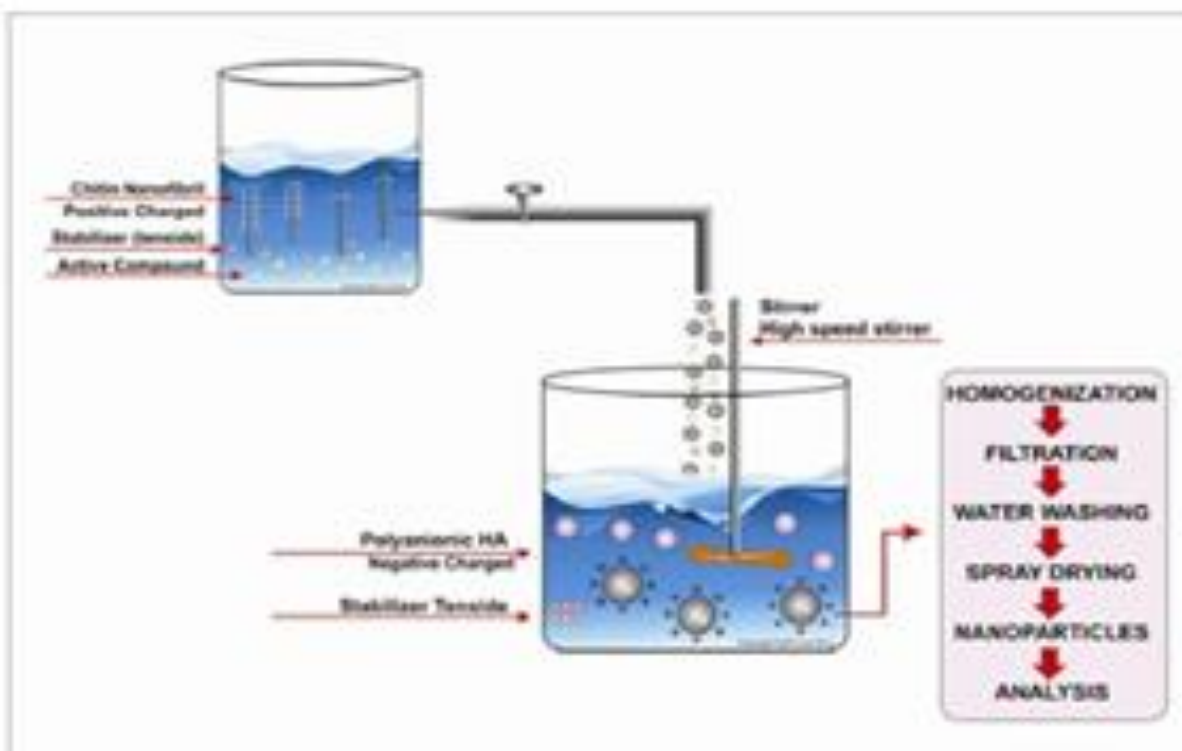

Cowive un teisu 


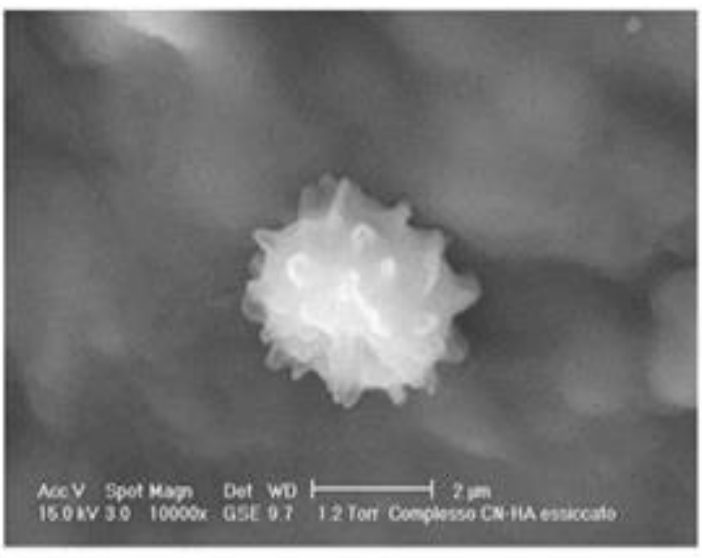

(a)

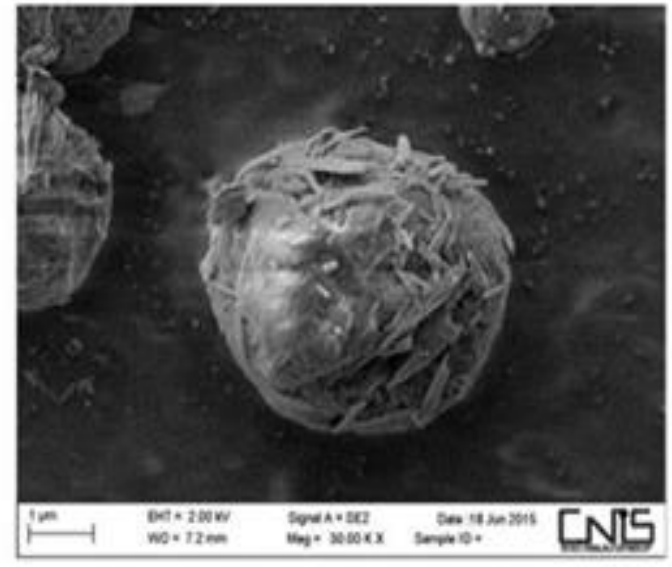

(b)

Figure 6: The ionic gelation method to obtain CN-LG Nanoparticles (up) and Nanoparticles of Hyaluronan on left (a) and CN-LG on right (b), below

\section{Lignin}

Weight of dry biomass on Earth is estimated to be 550 billion tons, 450 billion of which are represented by plants (Fig 7) [25].

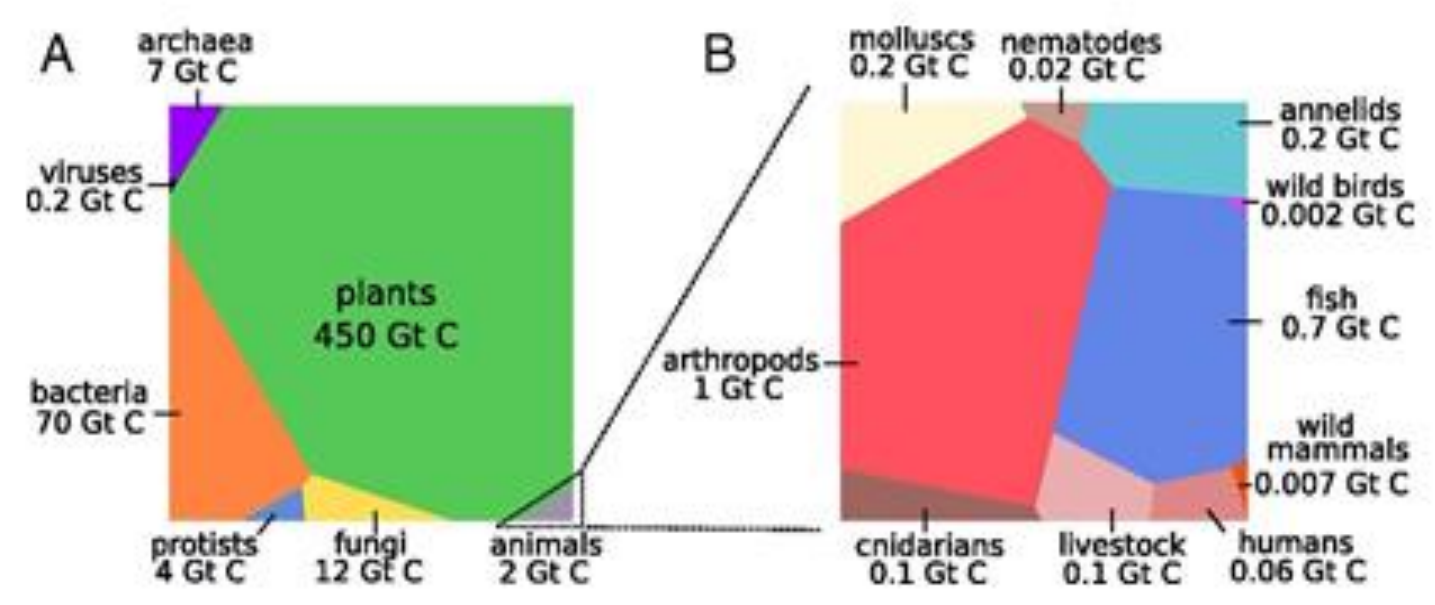

Figure 7: The Earth biomass distribution by different taxes (by courtesy of Bar- on et al [25])

It is however to remember that $75 \%$ of the plant biomass is composed of polysaccharides, $20 \%$ of which is represented by the biopolymer lignin.

Lignin, the structure of which is still unknown, is made up to $10-25 \%$ of a ligno-cellulosic biomass intimately bound like adhesive with cellulose and hemicellulose. It is represented by a complex phenolic threedimensional and highly cross-linked polymeric molecules, composed of three substitute phenolic compounds such as,coumaryl, coniferyl and sinapsyl alcohols(fig 8) [26]. 


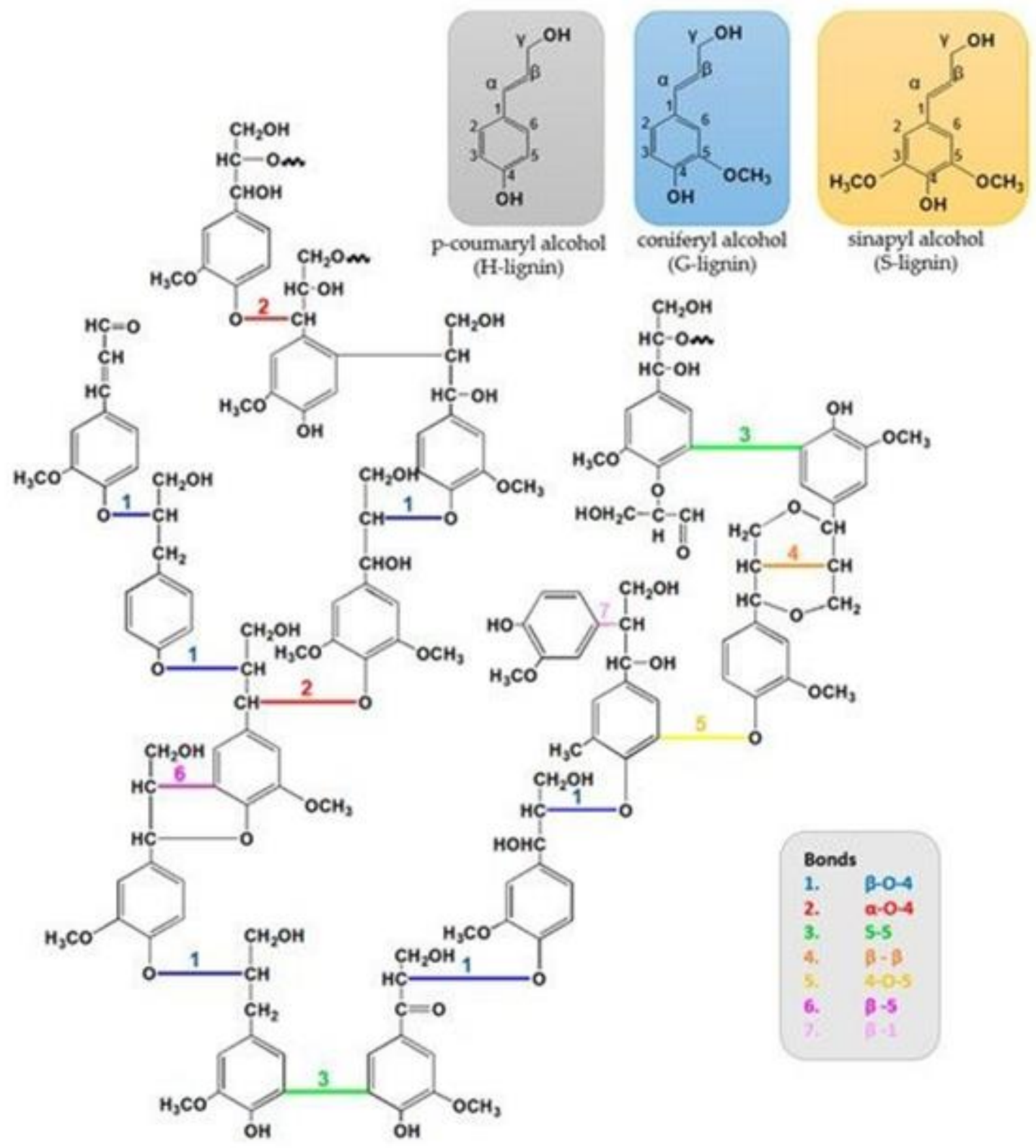

Figure 8: The proposed structure of lignin with its phenolic compounds

The polymer, as in cellulose or protein, lacks a regular and repetitive order ofmonomeric units, the composition of which varies according to the plant species. Thus lignin from herbaceous plants contains phydroxy phenyl, guaiacyl and syringyl units, whereas lignin from woody plants contains prevalently guaiacyl and syringyl ones [27].Unfortunately, this polymer available in large quantity as byproduct from the industrial processing of wood, energy crops, or agriculture residues, is until now commonly burned to obtain energy, while $2 \%$ only is used to produce low added value products, also if it represents an excellent source to produce valuable molecules and sustainable goods [28].However, lignin is considered an interesting antioxidant polymer to be used, for example, Slow down the ageing of both composites and biological systems [29]. Moreover, it has shown to possess an interesting UVA-UVB- absorbent ability attributable to the existence of abundance of chromophoric groups into its polymeric molecule [30]. Therefore, this specificactivity may be of interest to develop transparent UV-absorbent film as well as UVprotective innovative non-woven cosmeceuticals-tissues and dressings $[32,41]$ Just as for chitin, effectiveness and safeness of lignin depends from its source, physicochemical characteristics, purity and size, so that, extracted from wheat straw, it has shown, for example, to have the greatest thermal stability and highest char-yield. For the reported reasons and its antibacterial activity, being an electronegative polymer,lignin has been selected from our research group in its nano-size to make micro-nano blockpolymeric particles with the electropositive $\mathrm{CN}$ $[33,34]$.At the nano-scale, in fact, size is one of the more important criteria that governs bothphysicochemical and biological behaviour of the final product. It has been shown, for example, that the ability of chitin to modulate the immune response depends on its size:its medium size (4070 millimicrons) activates TNF and IL-17 production having a proinflammatory activity, whereas the small-size $(<40$ millimicrons $)$ stimulates the production of IL-10,showing an anti-inflammatory activity 
[34].On the other hand silver nanoparticles protect the human keratinocytes against UV/induced damage [35],as well as nanochitin(LG) exhibits enhanced physical and chemical properties relative to the bulk materials showing a large surface-area-to-volume ratio and a better antioxidant and antimicrobial activity [36].

\section{Chitin-Lignin particles and biodegradable tissue- carriers}

As shown by our previous studies [37, 38] this medical and cosmetic vehicle could represent an important part of any formulation, being fundamental for its effectiveness and safeness.

At this purpose for example, it is important for a formulation to predict how the vehicle' composition will affect the adsorption of the active ingredients into the skin controlling in advance the reactivity the product may have when applied on the different skin areas, or which might be the probable partition coefficient of the active ingredient, established between epidermis and the vehicle [39].Thus, the need to respect all the characteristics that a vehicle should have as reported on figure 9 ,considering also the active ingredients selected for the designed formulation.

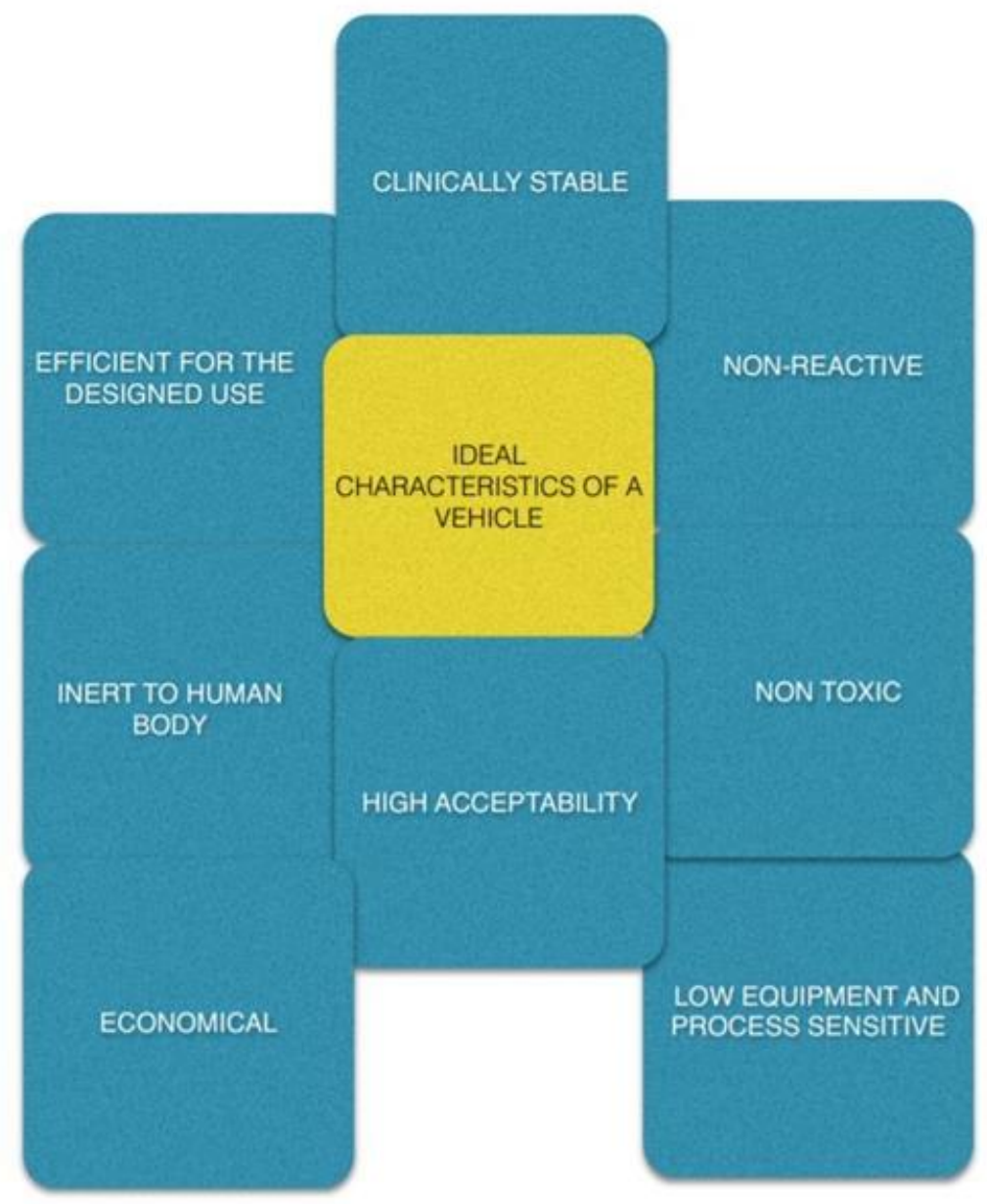

Figure 9

As the right vehicle should be however, the primary purpose of the vehicle is to enable the cosmetic activeingredients to be conveniently released at level of the different skin layers, at the dose and time designed. It is to underline, in fact, that many parameters influence the final product composition, including physicochemical characteristics of both the active ingredients and the carrier selected as well as the formulation type and the final structure of the product with the manufacturing conditions used [39].

At this purpose we have proposed to utilize smart non-woven tissues and films as innovative carriers for medical and cosmetic use [40, 11].These innovative carriers are made by natural polysaccharidecomposites embedding micro-nanoparticles(NPs) of CN-LG [41] which in turn may encapsulate different active ingredients, necessary to characterize the tissues' activity. Thus, for example, nano-structured silver nanoparticles and glycyrrhetic acid have been realized to make advanced medications $[16,42]$ while micro-nanoparticles of nicotinamide, vitamins $\mathrm{C}$ and $\mathrm{E}$ have beenused for making anti-aging cosmetic beauty masks (figure 10) [51, 42]. By the same technology, making pluri-strata tissues it should be possible to make biodegradable surgical masks [44-47],as well as it was possible toformulate gel and spray medications having an interesting skin repairing activity (figure 11) $[16,48,49]$. Regarding the surgical masks, the production and consumption of which have been increased for the COVID-19 pandemic, it is to remember not only the great waste caused from their use togetherwith the other the non-biodegradable single-use plastic means [50], but also the irritative allergic contact dermatitis provoked on the face of medicaldoctors and patients [51]. 


\section{Face Beauty Mask \\ ANTIINFLAMMATORY \\ ANTISEPTIC}

ANTIOXIDANT.
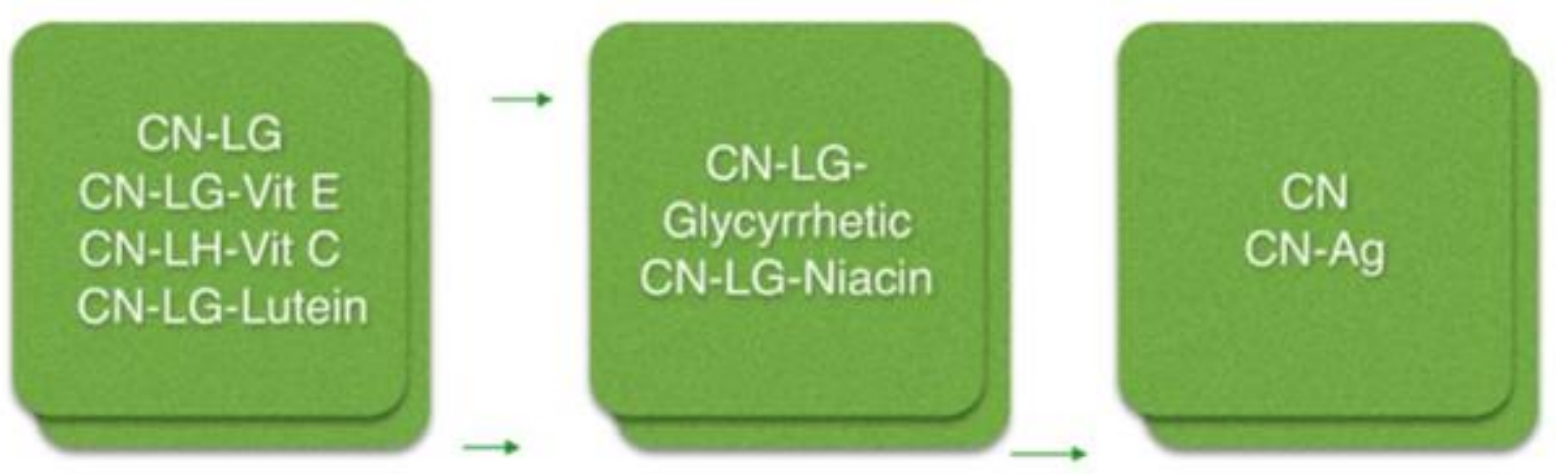

\section{Advanced Medications}

\section{Figure 10: Effectiveness of active ingredients encapsulated into different CN-LG complexes to be used by Beauty Masks or Advanced Medications.}
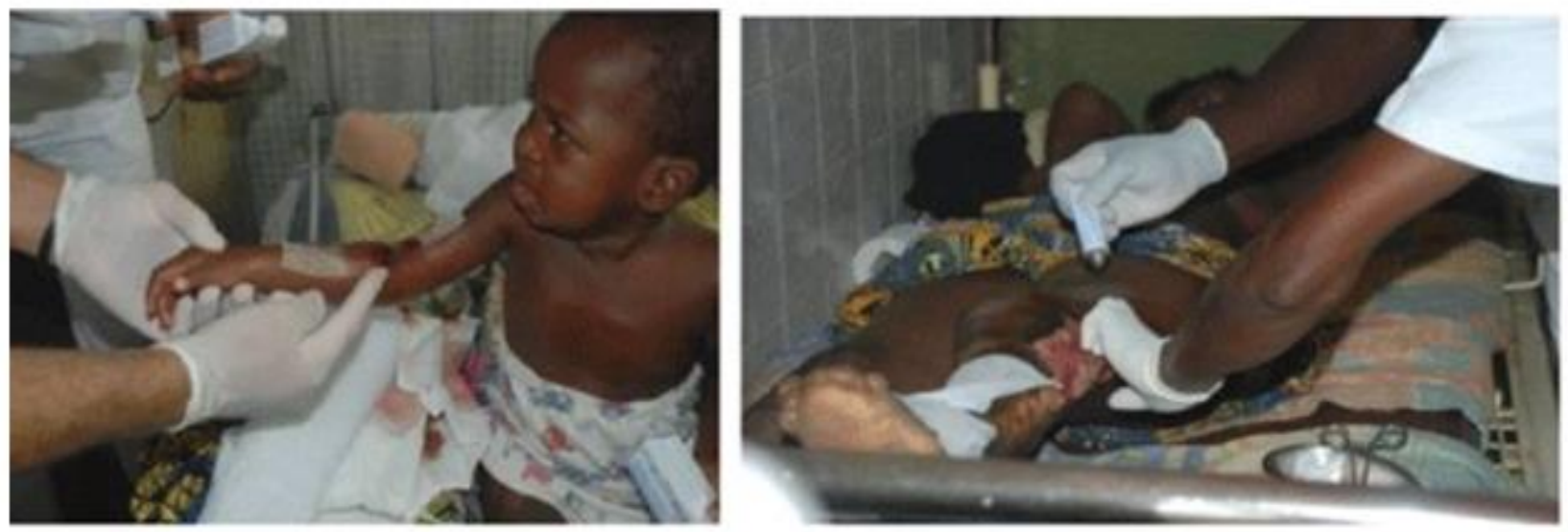

Figure 11: Skin repairing activity of a $C N-L G$ gel encapsulating chlorhexidine digluconate

\section{Conclusion}

As reported consumers, worried for the great waste and pollution invading our planet, are buying more cosmetics and food thinking this consumption useful for maintaining a nice look and an health ybody [52]. Consequently, they are considering to purchase products skin-and environmeally-friendly, characterized for their effectiveness, safeness and for the ingredients used rather than for the price [53]. Moreover, consumers are oriented not only for products based on natural ingredients and made by sustainable technologies, but also packed by biodegradable containers, knowing that packagings constitute roughly $46 \%$ of the global plastic waste invading the oceans (54). Thus our propose to use these bio-based carriers in substitution of the usual emulsions go in this direction. In fact, both the non-woven tissues and films embedded by the reported micro-nanoparticles not only are made by natural and biodegradable polymers and ingredients, including chitin and lignin, but may be packed by biodegradable paper or aluminium foils.

Moreover, differently from the emulsions these innovative cosmeceutical- tissues are free of preservatives, emulsifiers, fragrances, colors and other chemicals often cause of allergic and sensitizin gphenomena [10-16, 31-3337, 38, 40]. Least but not last, these innovative class of products are easily bio-degraded because the polymeric vehicles used to make the tissues as well as nano-chitin and nano-lignin utilized for the micro-Nanoparticles may be easily metabolized from the human enzymes, releasing molecule used as food 
and energy from the skin cells.

Author Contributions: Idea of manuscript PM; writing original draftpreparation PM, GM; writing-review and editing PM, GM, WEY, HDC; supervision PM, GM; All the authors have read andagreed to the publishing version of the manuscript.

\section{Funding: none}

Conflict of interest: the authors declared no conflict of interest

\section{References}

1. UN. (2019). World Population Ageing 2019: Highlights, Report of Department ofEconomic and Social Affairs United States, New York, USA.

2. Roberts R. (2021). Beauty Industry Trends \& Cosmetics Marketing: Statistics and Strategies for Yours Ecommerce Growth, Report byCommon Thread Collective.

3. Technavio. (2020). Health and Wellness Food Market 2029-2024IncreasingAdoption of Healthy Eating Habits to Boost Growth, TechnavioReport, London UK.

4. Kligman AM and Graham JA. (1986). Cosmetic Make-Over in Elderly Women. In: P Morganti and W Montagna (Eds) A new look at old skin: A challenge to cosmetology, International Ediemme Rome, Italy. 197-202.

5. Abeydeera LHVW, Mesthrige JW and Samarasinghalange TI. (2019). Global Research on Carbon Emissions: A Scientific Report, Sustainability. 11: 39-72

6. Landrigan PJ, Stegeman JJ, Fleming LE, Allemand D, Anderson DM, Backer LC, et al. (2020). Human Health and Ocean Pollution, Annals GlobalHealth. 86(1), 151:1-64

7. Morganti P and Chen Hong-Duo. (2015). From the Circular economy to agreen Economy .Note1.Chitin Nanfibrils as natural by-products to manage the human and Environment Ecosystem, J Appl Cosmetol. 33: 101-113

8. Curtain F (Ed). (2020). Breaking the Plastic Wave: A Comprensive assessment of pathways toward stopping ocean plastic pollution. The Pew Charitable Trusts and SYSTEMIQ Report.

9. EEA. (2020). Bio-waste in Europe-Turning Challenges into Opportunities, European Environment Agency ,Report , Luxemburg.

10. Morganti P, Morganti G and Coltelli MB. (2019). Chitin Nanomaterials and Nanocomposites for Tissue Repair. In AH Choi and B Ben- Nissan (Eds)Marine-derived Biomaterials for Tissue Engineeing Applications, Springer Singapore. 523-544

11. Tishchenko G, Morganti P, Stoller M, Kelnar I, Mikesova J, Kovarova J, et al. (2019). Chitin Nanofibrils-Chiosan Composite Films: Characteization and Properties. In: P Morganti (Ed) Bionanotechnology to Save the Environment, MDPI, Basel, Switzerland. 191-226.

12. Cinelli P, Coltelli MB, Signori F, Morganti P and Lazzri A. (2019). Cosmetic Packaging to Save the Envionment: Future Perspective, Cosmetics. 6(2): 26.

13. Morganti P, Chen Hong-Duo and Morganti G. (2020). Nanocosmetics:Future Perspective. In:A Nanda,S Nanda, TA Nguyen,S Rajendran and Y Slimani (Eds).Nanocosmetucs:Fundamentals, Appications and Toxicity, Elsevier, Amsterdam ,Netherlands. 455-481.

14. Morganti P, Morganti G and Palombo M. (2021). Research \& Inovation for Sustainable Products: Polysaccharides for a Smart Circular Economy atZero Waste, Clin Res Clin Trials. 33-37.

15. Morganti P and Stoller M. (2017). Chitin and Lignin: Natural Ingredients from Waste Materials to Make Innovative and Healthy Products for Humansand Plant, Chem Eng Trans. 60:
319-324.

16. Danti S, Trombi L, Fusco A, Azimi B, Lazzeri A, Morganti P, et al. (2019). Chitin Nanofibrils and Nanolignin as Functional Agents in Skin Regeneration, Int J Mol Sci. 20: 26-69.

17. Roberts G. (1998). (Ed) Chitin Chemistry, Macmillan, London, UK.

18. Coltelli MB, Aliotta L, Vannozzi A, Morganti P, Panariello L, Danti S et al. Properties and Skin Compatibility of Films Based on Poly(Lactic acid) (PLA) Bionanocomposites Incorporating Chitin Nanofibrils(CN),J FunctBiomater. 11-21.

19. Azimi B, Thomas L, Fusco A, Kalaoglu-Altan OI, Basnet P, Cinelli P et al. (2020). Electrosprayed Chitin Nanofibril Electrospun Polyhydroxyalkanoate Fiber Mesh as Functional Nonwoven for Skin, J Funct Biomater. 11(3): 62.

20. Ravi Kumar MN. (2000). A Review of Chitin and Chitosan Applications, ReactFunct Polym. 46: 1-27.

21. Ravi Kumar MNV, Muzzarelli RAA, Muzzarelli C, Sashiwa HA and Domb J. (2004). Chitosan Chemistry and Pharmaceutical Perspectives, Chem Rev. 104: 6017-6084.

22. Morganti P, Carezzi F, Del Ciotto P, Morganti G, Nunziata ML, Gao X, ChenHD, et al. (2014). Chitin Nanofibrils: A Natural Multifunctional Polymer .In: DA Phoenix and W Ahmed (Eds) Nanobiotechnology, OneCentral Press, Manchester, UK. 1-31.

23. Yudin VE, Dobrovolskaya IP, Neelov IM, Dresvyanina EN, Popryakhin PV et al. (2014). Wet Spinning Fibers Made of Chitosan and Chitin Nanofibrils, Carbohydr Polym. 108: 176182.

24. Morganti P. (2016). Use of Chitin Nanofibrils from Biomass for an Innovative Bioeconomy. In:J Ebohe' and W Ahmad (Eds)Nanofabrication Using Nanomaterials, One Central Press, Manchester, UK. 1-22.

25. Bar-On YM, Phillips R and Milo R. (2018). The Biomass Distribution on Earth, PNAS. 115(25): 6506-6511.

26. Lora JH. (2008). Industrial commercial lignins: Sources, properties and applications. In: M Belgacem and a Gandini (Eds) Monomers, Polymers and Composites from Renewable Resources,Elsevier, Oxford UK.225-241.

27. Buranov AU and Mazza G. (2008). Lignin in straw of herbaceous crops, IndCroos Prod. 28(3): 237-259.

28. Lora J and Glasser WG. (2002). Recent Industrial Applications of Lignin: A Sustainable Alternative to Nonrenewable Materials, J Polym Environ. 10(1-2): 39-48.

29. Arshanitsa A, Ponomarenko J, Dizhbite T, Andersone A, Gosselink RJA, Van Der Putten J, et al. (2013). Fractionation of technical lignins as a toolfor improvement of their antioxidant properties, J Anal Appl Pyrolysis. 103:78-85.

30. Qian Y, Qiu X and Zhu S. (2015). Lignin: a nature-inspired sun blocker for broad-spectrum sunscreens.,Green Chem. 17:320324.

31. Morganti P, Morganti G, Gagliardini A and Lohani A. (2021). From Cosmetics to Innovative Cosmeceutical-non-woven Tissues, Cosmetics. 8:65.

32. Morganti P, Qi RQ, Gagliardini A Morganti G and Coltelli MB. (2021). Natural Polymers for Biodegradable Dressings to Save the Environment, Int JNanotechnol Nanomd. 6(2):22-29.

33. Morganti P, Vannozzi A, Memic A, and Coltelli MB. (2021). Chitin and Lignin Waste in the Circular Economy. In: P Morganti and MB Coltelli Eds) An Introduction to the Circular Economy, Nova Sciences Publishers, New York, USA. 281-296.

34. Da Silva CA, Chalouni C, Williams A, Hartl D, Lee CG et al. (2009). Chitin is asuse-dependent regulator of macrophage TNF and IL-10 production, JImmunol. 182:3573-3580.

35. Arora S, Tyagi N, Bhardwaj A, Rusu L, Palanki R, Vig K et al. (2015). Silver Nanoparticles protect human keratinocytes against 
UVB radiation- induced DNA damage and apoptosis: potential for prevention of skincarcinogens, Nanomedicine. 11:1265-1275.

36. Wang Ji and Vermerris W. (2016). ntimicrobial Nanomaterials Derived fromNatural Products-A Review, Materials. 9:255.

37. Morganti P and Coltelli MB. (2019). A New Carrier for Advanced Cosmeceuticals, Cosmetics. 6:10.

38. Morganti P, Gagliardini A, and Morganti G. (2021). Nanochitin and Nanolignin: Activity and Effectiveness. In: P Morganti (Ed) Biofunctional Textiles for an Aging Skin-From the Bench to the Market, Lambert Academic Publishing. 333-370.

39. Wiechers JW. The Influence of Formulation Type on Skin Delivery. In:Skin Delivery Systems, JW Wieckers (Ed), Alluted PublishingCorporation,Carol Stream, IL, USA. 62-89.

40. Morganti P,Morganti G and Colao C. (2019). Biofunctional Textiles for AgingSkin, Biomedicines. 7:51.

41. Coltelli MB, Danti S, Trombi L, Morganti P, Donnarumma G, Baroni A et al.2018). Preparation of Innovative Skin Compatible Films to Release Polysaccharides for Biobased Beauty Masks, Cosmetics. 5(4): 70.

42. Triunfo M, Tafi E, uarnieri A, Scieuzo C,Hahn T, Zibek S, Salvia R, Falabella P. (2021). Insect Chtin-Based Nanomaterials for Innovative Cosmetucs and Cosmeveuticals, Cosmetics.8: 49.

43. Panariello L. Vannozzi A, Morganti P, Coltelli MB, and Lazzeri A. (2021). Biobasedand Eco-compatible Beauty Films Coated with Chitin Nanofibrils, Nanolignin and Vitamin E, Cosmetics. 8: 27.

44. Morganti P and Morganti G. (2020). Surgical \& Beauty Facial Masks: The NewWaste Problem of Post COVID-19, Biomed Sci $\&$ Tech Res.
45. Morganti P, Yudin VE, Morganti G and Coltelli MB. (2020). Cosmetics. 7(3): 68.

46. Morganti P and Morganti G. (2020). Post-COVUD19: Opportunity to ProduceBiodegradable Goods \& Surgical Masks to Save the Environment J Health Care Res. 1(3): 157-165.

47. Morganti P and Morganti G. ( 2020). Textile \& Waste: Will be COVID-19 aCatalyst for Changing? J Textile Eng \& Tech. 2(3): 26-31.

48. Mattioli-Belmonte M, Zizzi G, Lucarini F, Giantomassi G, Biagini G, Orlando F,et al. (2007). Chitin Nanofibrils Linked to Chitosan Glycolate asSpray, Gel, and Gauze, J Bioactive Comp Polym. 22: 525-538.

49. Mezzana P. (2008). Clinical Efficacy of a New Chitin Nanofibrils gel in WoundHealing, Acta Chir Plast. 50(3): 81-84.

50. Graulika K. Kohler A, Low C,Sutter J, Watson D, Mehlhart G et al. (2021). Impact of COVID-19 on Single-use Plastics and the Environment in Europe, Report, European Topic Centre on Waste and Materials in a GreenEconomy, Boeretang.

51. Park SJ, Han HS. (2021). Adverse Skin Reactions Due to Use of Face-Masks: AProspective Survey, JEADV.

52. Roberts R. (2021). Beauty Industry Trends \& Cosmetics Marketing: Statistics and Strategies for your Ecommerce Growth, Common Threads Collective Report.

53. Ridder M. (2020). Global Market Value for Natural and Personal Care from 2018to 2027, Statista Report.

54. Thevenon F, Carrol C and Sousa J (Eds). (2014). Plastic Debris in the Ocean, International Union for Conservation of Nature, GlobalMarine and Polar Programme, Gland, Switzerland.

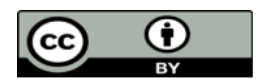

This work is licensed under Creative Commons Attribution 4.0 License
To Submit Your Article Click Here: Submit Manuscript

DOI: $10.31579 / 2578-8949 / 083$
Ready to submit your research? Choose Auctores and benefit from:

$>$ fast, convenient online submission

$>$ rigorous peer review by experienced research in your field

$>$ rapid publication on acceptance

$>$ authors retain copyrights

$>$ unique DOI for all articles

$>$ immediate, unrestricted online access

At Auctores, research is always in progress.

Learn more https://auctoresonline.org/journals/dermatology-anddermatitis 